\title{
Neuropsychological Profiles in Mild Cognitive Impairment due to Alzheimer's and Parkinson's Diseases
}

\author{
Erik Hessen ${ }^{\mathrm{a}, \mathrm{b}, *}$, Ane Løvli Stav ${ }^{\mathrm{a}}$, Eirik Auning ${ }^{\mathrm{c}}$, Per Selnes $^{\mathrm{a}}$, Linn Bloms $\emptyset^{\mathrm{b}}$, \\ Cathrine Emilie Holmeide ${ }^{b}$, Krisztina Kunszt Johansen ${ }^{\mathrm{a}}$, Carl Fredrik Eliassen ${ }^{\mathrm{a}, \mathrm{b}}$, \\ Ivar Reinvang ${ }^{\mathrm{b}}$, Tormod Fladby ${ }^{\mathrm{a}, \mathrm{d}}$ and Dag Aarsland ${ }^{\mathrm{e}, \mathrm{f}}$ \\ ${ }^{a}$ Department of Neurology, Akershus University Hospital, Lørenskog, Norway \\ ${ }^{\mathrm{b}}$ Department of Psychology, University of Oslo, Norway \\ ${ }^{\mathrm{c}}$ Department of Geriatric Psychiatry, Akershus University Hospital, Lørenskog, Norway \\ ${ }^{\mathrm{d}}$ Institute of Clinical Medicine, Campus Ahus, University of Oslo, Norway \\ 'Alzheimer's Disease Research Centre, Department of Neurobiology, Care Sciences and Society, \\ Karolinska Institutet, Novum, Stockholm, Sweden \\ ${ }^{\mathrm{f}}$ Center for Age-Related Diseases, Stavanger University Hospital, Stavanger, Norway
}

Accepted 11 March 2016

\begin{abstract}
.
Background: Neuropsychological comparisons between patients with mild cognitive impairment due to Parkinson's disease (MCI-PD) and Alzheimer's disease (MCI-AD) is mostly based on indirect comparison of patients with these disorders and normal controls (NC).

Objective: The focus of this study was to make a direct comparison between patients with these diseases.

Methods: The study compared 13 patients with MCI-PD and 19 patients with MCI-AD with similar age, education and gender. The participants were recruited and assessed at the same university clinic with equal methods.

Results: The main finding was that on group level, MCI-AD scored significantly poorer on learning and memory tests than MCI-PD, whereas MCI-PD were impaired on 1 of 3 measures of executive functioning.

Conclusion: MCI-AD performed poorer learning and memory tests, whereas MCI-PD only scored below the employed cut-off on one single executive test. In general, MCI-PD was noticeably less cognitively impaired than MCI-AD.

Keywords: Mild cognitive impairment, Parkinson's disease, Alzheimer's disease, neuropsychology, cerebrospinal fluid biomarkers
\end{abstract}

\section{INTRODUCTION}

Cognitive problems are common in early Parkinson's disease (PD). Different studies have classified 25 to $30 \%$ of non-demented patients with PD as having mild cognitive impairment (MCI) [1-3], and single-domain non-amnestic MCI occurs more

\footnotetext{
*Correspondence to: Erik Hessen, Department of Neurology, Akershus University Hospital, 1478 Lørenskog, Norway. Tel.: +4792097373; E-mail: erik.hessen@ nevropsykologi.no.
}

frequently than single-domain amnestic MCI in PD $[1,3,4]$. Seemingly in contrast to this, studies have shown that memory is the single cognitive function that most frequently is reduced in early PD $[3,5]$. In MCI likely due to Alzheimer's disease (AD), amnestic MCI (aMCI) is most common [6], although several studies suggest that patients with amnestic/multi domain MCI (amnestic impairment in addition to other cognitive deficits) may be at even greater risk of $\mathrm{AD}$ than patients with amnestic single 
domain MCI [7, 8]. These findings suggest both neuropsychological similarities and differences between MCI in PD (MCI-PD) and MCI due to AD (MCI$\mathrm{AD})$.

Neuropathology is heterogeneous in both conditions with partially overlapping findings. Based on autopsy findings in PD patients, Braak et al. [9] reported that the intraneuronal formation of Lewy inclusion bodies and Lewy neurites has a topographically predictable progression, starting in the brain stem, extending into the midbrain, affecting the substantia nigra, and subsequently affecting cortical areas. In addition to Lewy body pathology, the neuropathology in MCI-PD also includes cortical amyloid $\beta(\mathrm{A} \beta)$ plaques $[10,11]$. More recent detailed early-stage PD neuropathological studies have revealed broad pathological processes including frontal cortex oxidative and endoplasmatic stress [12-14]. Animal studies have shown that Lewy body pathology may stimulate the development of $A \beta$ plaques and vice versa [15]. Also, postmortem analysis has shown that many demented PD patients fulfill the neuropathological criteria of $\mathrm{AD}$ [16].

Though extra-temporal including frontal cortex often suffers from early amyloid pathology in early $\mathrm{AD}$, objective clinical manifestations are accompanied by memory network changes [17, 18]. In MCI-AD early amyloid $\beta(A \beta)$ may elicit synaptic dysfunction, neurodegeneration and finally detectable cognitive changes and functional decline associated with early dementia [19].

Low CSF A 342 and high total and phosphorylated tau (T- and P-tau) are part of MCI-AD diagnostic criteria $[6,20]$, and high CSF T-tau levels characterize patients developing AD at follow up [21]. Recently, a large post mortem study found that T-tau level, but not $A \beta$ plaques, predicted age onset of cognitive decline and $\mathrm{AD}$ [22]. In PD, CSF A $\beta 42$ may be slightly reduced compared to controls and associated to cognitive impairment [23-25], while T-tau and phosphorylated tau (P-tau) have been reported to be reduced or unchanged in PD without dementia and increased in PD with dementia [25, 26].

The referenced studies regarding neuropsychological differences and similarities are mainly based on indirect comparison of patients with each of these disorders with healthy controls. To our knowledge, only a couple of studies have compared neuropsychological profiles directly between patients in the early stages of these diseases. Guidi et al. [27] found that MCI-PD patients demonstrated inferior performances on a semantic questionnaire, whereas the
aMCI group displayed modest difficulties in a naming task. More relevant to the present is the study by Hildebrandt et al. [28]. They compared aMCI $(n=29)$ patients to mild cognitively impaired PD patients (MCI-PD) $(n=25)$ (Hoehn and Yahr scale: $3.4 \mathrm{SD}=0.5)$ and found that aMCI patients were impaired in episodic memory, while MCI-PD patients showed deficits in visuoconstruction and attention. However, in this study international consensus criteria for MCI or biomarkers were not used, making these findings difficult to interpret.

The present study aimed to add to the knowledge of cognitive function in MCI in PD compared to the recent core clinical criteria for MCI likely due to $\mathrm{AD}$, in addition to at least one pathological CSF biomarker. We hypothesized that both clinical groups would score poorer on neuropsychological measures than normal control patients would, that MCI-AD would score poorer than MCI-PD on measures of memory and that both clinical groups would achieve poor scores on non-amnestic/executive measures.

\section{METHODS AND MATERIALS}

The study protocol was approved by the SouthEastern Norway ethical committee for medical research. Written informed consent was obtained from all participants.

\section{Neuropsychological definition of MCI in the present study}

Both the PD and MCI-AD patients underwent neuropsychological assessment:

1. Memory: Delayed verbal recall (Rey Auditory Verbal Learning Test (RAVLT), [29, 30] and Delayed visual reproduction (Rey Complex Figure Test (RCFT) [31].

2. Aspects of executive functions: Divided attention (Trail Making Test-B (TMT-B) [32], Word fluency (Controlled Oral Word Association Test (COWAT) [33] and Response inhibition (Stroop Color-Word, D-KEFS) [34].

3. Visuospatial ability: Copy trial (Rey Complex Figure Test (RCFT) [31, 35].

We employed the clinical criteria for MCI recommended by NIA-AA [6]. Thus, to qualify as MCI, the score of at least one of the six neuropsychological subtests had to be in the impaired range, defined as $1.5 \mathrm{SD}$ or more below average, based on normative scores. The patients were categorized as (1) amnestic 
single-domain or (2) non-amnestic/executive singledomain MCI if either only memory or only nonamnestic/executive scores were below the selected cut-off criterion, and (3) multi-domain MCI if at least one memory and one non-amnestic/executive score were below cut-off.

\section{Inclusion and exclusion criteria}

The participants were recruited from parallel studies at Akershus University Hospital in Norway. Both clinical cohorts have previously been described $[25,36]$.

Twenty-nine patients (above 50 years old) with PD were recruited consecutively. Neurological examination and diagnosis, the unified Parkinson's disease rating scale (UPDRS) part III motor examination [37] and Hoehn and Yahr staging were performed by trained research physicians and movement disorder specialists. From this group, 13 patients were diagnosed with MCI-PD according to the neuropsychological definition, and included in the present analysis. Inclusion criteria were diagnosis of PD according to the UK Parkinson's Disease Society Brain Bank clinical diagnostic criteria [38], Hoehn and Yahr stage $<3$ and disease duration $<6$ years. None of the patients reported motor fluctuations or dyskinesias. All subjects had a pathological single photon emission computed tomography (SPECT) using an ioflupane (123I) biomarker (DaTSCAN). Total daily levodopa equivalent dose (LED) was calculated [39].

From a parallel study 25 patients (above 50 years old) with MCI due to Alzheimer's disease (according to the core clinical NIA-AA criteria) [6] were included [36]. They underwent screening for memory, disorientation, abstract thinking, visuospatial ability, language, sensory aphasia, visual agnosia, and apraxia [40, 41], as well as word fluency, interference, and numeral-letter items [42]. Additionally, the cognitive screening included items from the Neurobehavioral Cognitive Status Examination [43] as well as Mini-Mental State Exam (MMSE) [44]. Patients with subjective memory complaints and results below recommended cutoff on the cognitive screening were classified as MCI [45]. One of the patients had MMSE $=23$, but was included as she had normal employment and was self-sufficient. In addition, all the patients had at least one abnormal CSF AD biomarker (A $\beta 42$, P-tau or T-tau) $[25,46]$ and thus were categorized as MCI-AD in this study. From this group, 19 qualified as MCI according to the neuropsy- chological criterion, and were included in the present analysis.

Exclusion criteria for both clinical groups were dementia and other somatic or psychiatric disease that might contribute to cognitive impairment (including drug abuse, moderate or severe depression, solvent exposure, ischemic stroke and active cancer) $[25,36$, 47]. Also, patients included in the MCI-AD group did not fulfill criteria for PD, Lewy body, frontotemporal or vascular dementia.

Normal control patients (NC) were also included. These were recruited before lumbar puncture in conjunction with orthopedic surgery. Inclusion criteria were normal cognition based on Mini-Mental State Exam (MMSE) $\geq 28$ and scores above 1,5 SD below average on four neuropsychological tests: Delayed recall from RAVLT [29, 30], the TMT-B [32], the COWAT [33] and the Stroop Color-Word test [34]. This is consistent with criteria recommended by the NIA-AA [6]. By definition, all the normal controls had neuropsychological scores in the normal range. Exclusion criteria were as for $\mathrm{PD}$ and the MCI group in addition to significant subjective cognitive decline.

\section{Cerebrospinal fluid biomarkers}

Following lumbar puncture and standardized handling, CSF Aß42, T-tau and P-tau were analyzed with ELISA (Fujirebio Europe, previously Innogenetics) in all patients. CSF Aß42 was considered pathological if $\leq 600 \mathrm{ng} / \mathrm{L}, \mathrm{P}$-tau if $\geq 80 \mathrm{ng} / \mathrm{L}$, and T-tau if $>450 \mathrm{ng} / \mathrm{L}$ [25].

\section{Statistical analysis}

The Statistical Package for Social Sciences (SPSS 22.0) was used for all statistical analyses. First, descriptive statistics of the demographic, clinical and cognitive characteristics of the patient populations were computed. Chi-square tests were performed to compare gender differences. A one-way ANOVA was performed to compare differences between the three groups. The assumption of homogeneity was violated with regard to T-tau and P-tau, however more robust tests of equality of means revealed significant differences (Welch and Brown-Forsythe) and Games-Howell post hoc testing was conducted. Independent t-tests were employed to compare differences between MCI-PD and MCI-AD on the copy trial and delayed recall trial of RCFT. 


\section{RESULTS}

\section{Demographic and clinical characteristics}

Demographic and clinical variables of the 56 patients who took part in the study are shown in Table 1.

NC, MCI-PD and MCI-AD did not differ significantly with regard to age, gender and education. The NC achieved similar results as MCI-PD on the MMSE, T-tau, P-tau, Stroop Color Word (raw scores) and COWAT (t-scores), but scored significantly better than MCI-PD on the other clinical variables. The $\mathrm{NC}$ achieved similar results as MCI-AD on COWAT (raw scores and t-scores), but scored significantly better than MCI-AD on all other clinical variables. The MMSE score was lower and all the CSF values were significantly more pathological in the MCI-AD compared to the MCI-PD group. For the MCI-PD group all the mean CSF values were in the normal range while they as expected were in the pathological range for MCI-AD [41]. Not shown in Table 1 are specific characteristics for the MCI-PD group (mean and $\mathrm{SD})$ : Disease duration: 2.1 years $(\mathrm{SD}=0.8)$, UPDRS part III motor score: $17.7(\mathrm{SD}=7.4)$, Hoehn and Yahr stage: $1.7(\mathrm{SD}=0.6)$ and total daily levodopa equivalent dose: $310.4(\mathrm{SD}=177.3)$. With regard to neuropsychology, the NC group achieved average group scores, as expected. The MCI-AD achieved significantly poorer raw scores on verbal learning (RAVLT 1-5, not included in the neuropsychological MCI algorithm) and delayed recall compared to MCI-PD. The MCI-AD obtained significantly poorer T-scores (below 1.5 SD below average norms) on all three learning and memory tests than the MCI-PD group, while the opposite was true with regard to divided attention (TMT B). Apart from that, the two groups achieved similar and average scores (Fig. 1).

Table 2 shows the frequencies of MCI categories defined by neuropsychological test scores for MCI-PD and MCI-AD. As expected there were more participants with amnestic single-domain MCI in the MCI$\mathrm{AD}$ group than in MCI-PD (57.9\% versus 30.8\%) and more non-amnestic/executive single-domain in MCI$\mathrm{PD}$ than in MCI-AD (38.5\% versus $10.5 \%$ ). However, none of these differences were significant.

\section{DISCUSSION}

The focus of the present study was to compare neuropsychological function in MCI-PD with MCI-AD defined by clinical and biological criteria. The key finding was that MCI-AD, on group level, scored significantly poorer on verbal learning and memory as well as visual memory than MCI-PD, who achieved average verbal learning and memory scores, and slightly below average on visual memory, according to norms. With regard to divided attention, the result was opposite as MCI-PD obtained a poor group score, about $1 \mathrm{SD}$ poorer than MCI-AD. While the distribution of amnestic, non-amnestic/executive and multi-domain MCI were quite similar in MCI-PD, the distribution of MCI was different in MCI-AD, dominated by amnestic MCI as well as multi-domain MCI. The first part of the hypothesis that MCI-AD would score poorer than MCI-PD on measures of memory was confirmed, while the second part, suggesting that both groups would achieve poor scores on non-amnestic/executive measures, was not. The NC were recruited based on neuropsychological scores in the normal range. Thus, by definition, superior performance was expected in this group, and the results in accordance with this will not be discussed further.

A strength of the study is the direct comparison of patients with MCI-PD and MCI-AD, based on equal neurological, cognitive and biological assessment (including CSF biomarkers) conducted at the same university hospital clinic. Methodologically this is advantageous compared to studies that mainly employ indirect comparison of patients with these disorders.

The present study employed the Albert et al. [6] criteria for MCI due to $\mathrm{AD}$ rather than the proposed criteria by Litvan et al. for MCI in PD [48]. We employed an abbreviated cognitive assessment and categorization of the PD group according to the Litvan et al. criteria (level I) only classified two PD patients as MCI-PD (impairment on at least two tests) as opposed to 13 based on the Albert et al. [6] criteria (impairment on at least one test). Thus, comparison of MCI in the two groups was only possible based on the most lenient of these MCI criteria. Although the Albert et al. criteria [6] were developed for detection of MCI due to $\mathrm{AD}$, they represent a well-defined method for separation between average and mildly impaired cognitive function based on a brief test battery, regardless of etiology.

One might question the representativeness of the small clinical groups in the present study. However, the patients were prospectively recruited from a public hospital and thus representative for patients referred to specialist treatment in a natural population. That said, larger groups would have strengthened the findings. This is particularly true for MCI-PD as this group 
Table 1

Demographical and clinical data of the study groups based on neuropsychological assessment

\begin{tabular}{|c|c|c|c|c|c|}
\hline $\begin{array}{l}\text { Demographical and } \\
\text { clinical data }\end{array}$ & $\begin{array}{l}\mathrm{NC}(1) \\
N=25\end{array}$ & $\begin{array}{l}\text { MCI-PD (2) } \\
\quad N=13\end{array}$ & $\begin{array}{c}\text { MCI-AD 3) } \\
\quad N=19\end{array}$ & & $\begin{array}{c}P \text {-value } \\
\text { (chi-square) }\end{array}$ \\
\hline \multirow[t]{2}{*}{ Female $(\%)$} & $9(36)$ & $3(23)$ & $11(58)$ & & $\begin{array}{l}1 \text { vs. } 2=.656 \mathrm{n} . \mathrm{s} . \\
1 \text { vs. } 3=.255 \mathrm{n} . \mathrm{s} \\
2 \text { vs. } 3=.110 \mathrm{n} . \mathrm{s}\end{array}$ \\
\hline & & & & $\begin{array}{l}\text { ANOVA } \\
P \text {-values }\end{array}$ & $\begin{array}{c}\text { Post hoc } p \text {-value } \\
\text { (Tukey) (Games Howell for } \\
\text { P-tau and T-tau) } \\
\end{array}$ \\
\hline Age (SD, range) & $63.6(7.2,52-77)$ & $67.2(4.1,61-73)$ & $66.7(4.9,58-76)$ & 0.123 & $\begin{array}{l}1 \text { vs. } 2=.187 \mathrm{n} . \mathrm{s} . \\
1 \text { vs. } 3=0.217 \mathrm{n} . \mathrm{s} \\
2 \text { vs. } 3=0.964 \mathrm{n} . \mathrm{s}\end{array}$ \\
\hline Education (SD, range) & $13.6(3.4,8-18)$ & $11.5(2.8,8-16)$ & $13.9(3.0,7-18)$ & 0.153 & $\begin{array}{l}1 \text { vs. } 2=0.733 \text { n.s. } \\
1 \text { vs. } 3=0.129 \text { n.s } \\
2 \text { vs. } 3=0.433 \text { n.s }\end{array}$ \\
\hline MMSE (SD, range) & $29.1(0.8,28-30)$ & $28.5(1.2,26-30)$ & $27.3(1.6,23-30)$ & 0.001 & $\begin{aligned} 1 \text { vs. } 2 & =0.129 \text { n.s. } \\
1 \text { vs. } 3 & =\mathbf{0 . 0 0 1}^{* *} \\
2 \text { vs. } 3 & =\mathbf{0 . 0 2 3}^{*}\end{aligned}$ \\
\hline $\mathrm{A} \beta 42, \mathrm{ng} / \mathrm{l}(\mathrm{SD}$, range $)$ & $\begin{array}{c}1084.7 \\
(198.3,772-1500)\end{array}$ & $\begin{array}{c}874.8 \\
(153.1,707-1280)\end{array}$ & $\begin{array}{c}518.4 \\
(105.7,302-726)\end{array}$ & 0.001 & $\begin{array}{l}1 \text { vs. } 2=\mathbf{0 . 0 0 1}^{* *} \\
1 \text { vs. } 3=\mathbf{0 . 0 0 1}^{* *} \\
2 \text { vs. } 3=\mathbf{0 . 0 0 1}^{* *}\end{array}$ \\
\hline P-tau, ng/l (SD, range) & $\begin{array}{c}48.2 \\
(13.5,26-70)\end{array}$ & $\begin{array}{c}48.0 \\
(34.9,25-155)\end{array}$ & $\begin{array}{c}107.0 \\
(49.0,54-238)\end{array}$ & 0.001 & $\begin{aligned} 1 \text { vs. } 2 & =0.857 \text { n.s. } \\
1 \text { vs. } 3 & =\mathbf{0 . 0 0 1}^{* *} \\
2 \text { vs. } 3 & =\mathbf{0 . 0 0 1}^{* *}\end{aligned}$ \\
\hline T-tau, ng/l (SD, range) & $\begin{array}{c}296.0 \\
(103.4,114-453)\end{array}$ & $\begin{array}{c}262.5 \\
(130.7,119-566)\end{array}$ & $\begin{array}{c}578.3 \\
(338.1,248-1407)\end{array}$ & 0.001 & $\begin{aligned} 1 \text { vs. } 2 & =0.655 \text { n.s. } \\
1 \text { vs. } 3 & =\mathbf{0 . 0 0 1}^{* *} \\
2 \text { vs. } 3 & =\mathbf{0 . 0 0 1}^{* *}\end{aligned}$ \\
\hline $\begin{array}{l}\text { Neuropsychological tests - } \\
\text { raw scores (SD, range) }\end{array}$ & & & & & \\
\hline RAVLT learning trial $1-5$ & $45.3(8.6,30-61)$ & $36.2(9.3,18-47)$ & $28.3(8.5,14-42)$ & 0.001 & $\begin{array}{l}1 \text { vs. } 2=\mathbf{0 . 0 1 0}^{* *} \\
1 \text { vs. } 3=\mathbf{0 . 0 0 1}^{* *} \\
2 \text { vs. } 3=\mathbf{0 . 0 3 9}^{*}\end{array}$ \\
\hline RAVLT delayed recall & $9.0(2.1,5-13)$ & $6.3(2.5,3-12)$ & $2.8(2.9,0-9)$ & 0.001 & $\begin{array}{l}1 \text { vs. } 2=\mathbf{0 . 0 0 7}^{* *} \\
1 \text { vs. } 3=\mathbf{0 . 0 0 1}^{* *} \\
2 \text { vs. } 3=\mathbf{0 . 0 0 1}^{* *}\end{array}$ \\
\hline RCFT delayed recall & & $9.4(6.1,1-20)$ & $5.9(4.1,0-19)$ & & 0.059 ( $t$-test) \\
\hline COWAT & $41.4(8.6,23-59)$ & $30.1(9.8,18-49)$ & $36.5(13.6,6-63)$ & 0.012 & $\begin{array}{l}1 \text { vs. } 2=\mathbf{0 . 0 0 9}^{* *} \\
1 \text { vs. } 3=0.302 \mathrm{n} . \mathrm{s} \\
2 \text { vs. } 3=0.233 \mathrm{n} . \mathrm{s}\end{array}$ \\
\hline TMT B & $82.3(35.8,40-159)$ & $207.6(93.1,75-349)$ & $150.3(114.7,60-531)$ & 0.001 & $\begin{array}{c}1 \text { vs. } 2=\mathbf{0 . 0 0 1}^{* *} \\
1 \text { vs. } 3=\mathbf{0 . 0 2 9}^{*} \\
2 \text { vs. } 3=0.149 \text { n.s }\end{array}$ \\
\hline Stroop Color-Word & $57.2(15.6,19-94)$ & $80.3(17.9,55-110)$ & $94.8(77.9,53-400)$ & 0.034 & $\begin{array}{l}1 \text { vs. } 2=0.316 \mathrm{n} . \mathrm{s} \\
1 \text { vs. } 3=\mathbf{0 . 0 2 9} * * \\
2 \text { vs. } 3=0.667 \mathrm{n} . \mathrm{s}\end{array}$ \\
\hline $\begin{array}{l}\text { RCFT copy trial } \\
\text { Neuropsychological tests - } \\
\text { T scores (SD, range) }\end{array}$ & & $27.1(9.7,3-35)$ & $28.1(7.2,5-35)$ & & 0.740 (t-test) \\
\hline RAVLT learning trial 1-5 & $52.8(11.8,35-82)$ & $42.5(12.8,17-62)$ & $32.6(9.8,16-46)$ & 0.001 & $\begin{array}{c}1 \text { vs. } 2=\mathbf{0 . 0 2 9}^{*} \\
1 \text { vs. } 3=\mathbf{0 . 0 0 1}^{* *} \\
2 \text { vs. } 3=\mathbf{0 . 0 5 5 n . s}^{*}\end{array}$ \\
\hline RAVLT delayed recall & $51.6(9.1,37-75)$ & $42.8(8.3,31-60)$ & $30.7(10.2,21-51)$ & 0.001 & $\begin{array}{l}1 \text { vs. } 2=\mathbf{0 . 0 . 2 1}^{*} \\
1 \text { vs. } 3=\mathbf{0 . 0 0 1}^{* *} \\
2 \text { vs. } 3=\mathbf{0 . 0 0 2}^{* *}\end{array}$ \\
\hline RCFT delayed recall & & $37.2(14.7,20-62)$ & $28.3(7.1,20-42)$ & & $0.029^{*}(t$-test $)$ \\
\hline COWAT & $50.7(6.8,37-64)$ & $43.2(8.2,33-58)$ & $48.6(14.5,21-79)$ & 0.109 & $\begin{array}{l}1 \text { vs. } 2=0.091 \mathrm{n} . \mathrm{s} . \\
1 \text { vs. } 3=0.782 \mathrm{n} . \mathrm{s} \\
2 \text { vs. } 3=0.315 \mathrm{n} . \mathrm{s}\end{array}$ \\
\hline TMT B & $52.1(9.7,35-68)$ & $28.8(16.2,10-52)$ & $40.4(12.2,10-57)$ & 0.001 & $\begin{array}{l}1 \text { vs. } 2=\mathbf{0 . 0 0 1}^{* *} \\
1 \text { vs. } 3=\mathbf{0 . 0 1 0}^{* *} \\
2 \text { vs. } 3=\mathbf{0 . 0 3 1}^{*}\end{array}$ \\
\hline Stroop Color-Word & $55.8(9.2,37-77)$ & $44.5(10.2,27-57)$ & $43.6(13.6,10-60)$ & 0.001 & $\begin{array}{c}1 \text { vs. } 2=\mathbf{0 . 0 1 1}^{* *} \\
1 \text { vs. } 3=\mathbf{0 . 0 0 2}^{* *} \\
2 \text { vs. } 3=0.972 \mathrm{n} . \mathrm{s} \\
0.950 \text { ( } t \text {-test })\end{array}$ \\
\hline
\end{tabular}




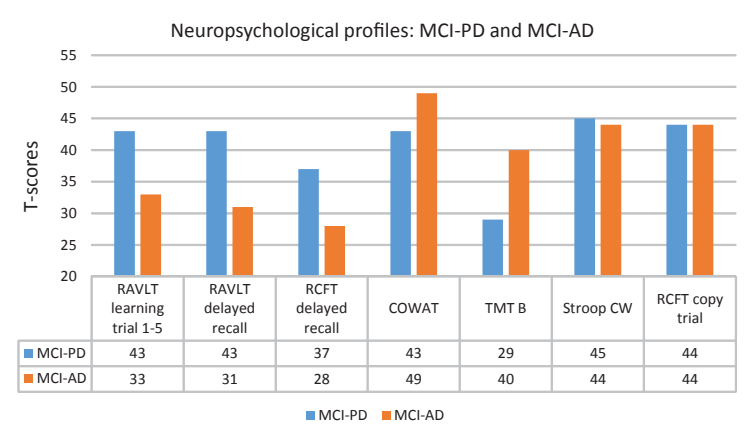

Fig. 1. Neuropsychological profiles for MCI-PD and MCI-AD.

is known to be highly heterogeneous with some studies demonstrating greater amnestic deficits, and others greater non-amnestic deficits [1,3-5].

The finding that MCI-AD scored significantly poorer on learning and memory tasks than MCIPD was as expected according to our hypothesis. This finding was in accord with the other study by Hildebrandt et al. that compared aMCI directly with MCI-PD [28]. The results in the Hildebrandt et al. study were almost inevitable as their comparison group was preselected based on objective memory impairment. To a certain degree, this kind of circularity is also relevant for the present study. Although we did not preselect the MCI-AD patients based on memory impairment, it is well established that memory impairment is a key feature of MCI-AD [6] and indeed, all the MCI-AD patients in our study did report subjective memory symptoms.

Additionally, the Hildebrandt et al. study [28] found that only MCI-PD showed deficits in visuoconstruction. In the present study, no impairment in visuospatial ability/visuoconstruction was evident in any of the groups. Different findings may be related to several factors. The two studies employed different measures of visuoconstructive ability, and different normative data. In this study we used the copy trial of RCFT, while Hildebrandt et al. [28] employed the Constructional praxis task from the CERAD battery [49]. Furthermore, the mean age of the MCI-PD group in the Hildebrandt et al. study was higher than in our study (71 years versus 67 years). Additionally, the Hoehn and Yahr scale in the Hildebrandt et al. study was 3.4 versus 1.7 in the present study, indicating more advanced PD in the Hildebrandt et al. study. In both studies, patients with MCI-PD achieved poor scores on measures of attention. Again, the employed measures, normative data and age were different. Hildebrandt et al. employed ZVT [50] (comparable to Trail Making Test A) [32] and Digit Span Forward from the Wechlser Memory Scale-R [51], while the present study employed Trail Making test B [32]. Digit Span Forward is considered to measure freedom of distractibility [52] and the trail making tests involve complex visual scanning and has a motor component that makes a strong contribution to success [53]. While digit span may be a relatively pure test of attention, the same cannot be said about the trail making tasks, especially when employed in a PD population. Motor problems in PD will indisputably influence performance on these kinds of tasks. Thus, based on the many skills necessary for success on TMT B, there is reason to be cautious about attributing poor results on this task only to attention problems in the present PD group. Nevertheless, the PD patients in this study were in early stages with mild to moderate motor symptoms, and it is difficult to say to what extend this affected the results. The lack of non-motor dependent attention measures may be considered a limitation with the present study.

The literature suggests both differences and similarities between MCI-AD and MCI-PD with regard to neuropathology and neuropsychology. Largely, the present data suggest significant differences between the two conditions, in agreement with most findings in the literature. A factor not considered is whether the two clinical groups are assessed at corresponding stages in their respective development or whether one condition is in a more advanced stage than the other, and that they eventually both will progress and become more similar with regard to neuropsychological dysfunction. The study of Hildebrandt et al. [28] shed some light on this as they also compared neuropsychological function in $\mathrm{AD}$ dementia and Parkinson dementia (PDD). In these more advanced

Table 2

Frequencies of MCI categories defined by neuropsychological test scores in the PD and MCI-AD groups

\begin{tabular}{|c|c|c|c|}
\hline MCI categories & $\begin{array}{c}\text { MCI-PD } \\
N=13\end{array}$ & $\begin{array}{c}\text { MCI-AD } \\
N=19\end{array}$ & $\begin{array}{c}P \text {-value } \\
\text { (chi-square) }\end{array}$ \\
\hline Amnestic single-domain $(\mathrm{N}, \%)$ & $4(30.8)$ & $11(57.9)$ & 0.25 \\
\hline Non-amnestic/Executive single-domain (N, \%) & $5(38.5)$ & $2(10.5)$ & 0.15 \\
\hline Multi-domain MCI $(\mathrm{N}, \%)$ & $4(30.8)$ & $6(31.6)$ & 1.0 \\
\hline
\end{tabular}


stages, both AD and PDD were similarly impaired on tests for language, attention and visuoconstruction, but still only the AD patients showed a memory impairment, similar to the aMCI patients. While neuropsychology is not the correct tool to reveal specific mechanisms of neuropathology, both the present data and the findings of the Hildebrandt et al. study suggest definite differences between the two conditions.

We have recently found associations between white matter integrity in prefrontal areas and executive and visuospatial ability [54], CSF A 342 and memory and response inhibition [25] as well as smaller hippocampal subfields and poorer memory and visuospatial function [55]. This suggests that although the MCI-PD patients as a group are less impaired on neuropsychological tests than MCI-AD, and have normal CSF biomarker levels according to cutoffs, there are already ongoing neuropathological processes, which may lead to cognitive decline in the future. Longitudinal data from this prospective study will clarify the role of brain changes and progression of cognitive decline.

In conclusion, by direct neuropsychological comparison the present study found that MCI-AD scored significantly poorer on learning and memory tests than MCI-PD, while MCI-PD were significantly poorer on one of three measures of executive function. In general, MCI-PD was less cognitively impaired than MCI-AD. This is supported by normal mean CSF values in the MCI-PD group and abnormal mean CSF values in the MCI-AD group.

\section{CONFLICT OF INTEREST}

Erik Hessen: none

Ane Løvli Stav: none

Eirik Auning: none

Per Selnes: none

Linn Bloms $\varnothing$; none

Cathrine Emilie Holmeide; none

Krisztina Kunszt Johansen: none

Carl Fredrik Eliassen: none

Ivar Reinvang: none

Tormod Fladby: none.

Dag Aarsland: Has received honoraria or research support from Lundbeck, Inc., Novartis, GE Healthcare, and GlaxoSmithKline; serves on the editorial boards of International Psychogeriatrics, Movement Disorders, and the Journal of Neurology, Neurosurgery, and Psychiatry.

\section{REFERENCES}

[1] Litvan I, Aarsland D, Adler CH, Goldman JG, Kulisevsky J, Mollenhauer B, Weintraub D (2011) MDS Task Force on mild cognitive impairment in Parkinson's disease: Critical review of PD-MCI. Mov Disord, 26, 1814-1824.

[2] Tröster AI (2011) A précis of recent advances in the neuropsychology of mild cognitive impairment(s) in Parkinson's disease and a proposal of preliminary research criteria. J Int Neuropsychol Soc, 17, 393-406.

[3] Aarsland D, Bronnick K, Williams-Gray C, Weintraub D, Marder K, Kulisevsky J, Emre M (2010) Mild cognitive impairment in Parkinson disease: A multicenter pooled analysis. Neurology, 75, 1062-1069.

[4] Aarsland D, Brønnick K, Larsen JP, Tysnes OB, Alves G (2009) Cognitive impairment in incident, untreated Parkinson disease: The Norwegian ParkWest Study. Neurology, 72, 1121-1126.

[5] Sollinger AB, Goldstein FC, Lah JJ, Levey AI, Factor SA (2010) Mild cognitive impairment in Parkinson's disease: Subtypes and motor characteristics. Parkinsonism Relat Disord, 16, 177-180.

[6] Albert MS, DeKosky ST, Dickson D, Dubois B, Feldman HH, Fox NC, Phelps CH (2011) The diagnosis of mild cognitive impairment due to Alzheimer's disease: Recommendations from the National Institute on AgingAlzheimer's Association workgroups on diagnostic guidelines for Alzheimer's disease. Alzheimers Dement, 7, 270-279.

[7] Nordlund A, Rolstad S, Klang O, Edman A, Hansen S, Wallin A (2010) Two-year outcome of MCI subtypes and aetiologies in the Goteborg MCI study. J Neurol Neurosurg Psychiatry, 81, 541-6.

[8] Weiner MW, Veitch DP, Aisen PS, Beckett LA, Cairns NJ, Green RC, Harvey D, Jack CR, Jagust W, Liu E, Morris JC, Petersen RC, Saykin AJ, Schmidt ME, Shaw L, Shen L, Siuciak JA, Soares H, Toga AW, Trojanowski JQ, Alzheimer's Disease Neuroimaging Initiative (2013) The alzheimer's disease neuroimaging initiative: A review of papers published since its inception. Alzheimers Dement, 9 , 111-194.

[9] Braak H, Braak E, Yilmazer D, de Vos RA, Jansen EN, Bohl J (1996) Pattern of brain destruction in Parkinson's and Alzheimer's diseases. J Neural Transm, 103, 455-490.

[10] Adler CH, Caviness JN, Sabbagh MN, Shill HA, Connor DJ, Sue L, Evidente VG, Driver-Dunckley E, Beach TG (2010) Heterogeneous neuropathological findings in Parkinson's disease with mild cognitive impairment. Acta Neuropathol, 120, 827-828.

[11] Jellinger KA (2010) Neuropathology in Parkinson's disease with mild cognitive impairment. Acta Neuropathol, 120, 829-830.

[12] Ferrer I, Martinez A, Blanco R, Dalfó E, Carmona M (2011) Neuropathology of sporadic Parkinson disease before the appearance of parkinsonism: Preclinical Parkinson disease. J Neural Transm (Vienna), 118, 821-839.

[13] Ferrer I, López-Gonzalez I, Carmona M, Dalfó E, Pujol A, Martínez A (2012) Neurochemistry and the non-motor aspects of PD. Neurobiol Dis, 46, 508-526.

[14] Tassone F, Guarnieri A, Castellano E, Baffoni C, Attanasio R, Borretta G (2015) Parathyroidectomy halts the deterioration of renal function in primary hyperparathyroidism. J Clin Endocrinol Metab, 100, 3069-3073.

[15] Clinton LK, Blurton-Jones M, Myczek K, Trojanowski JQ, LaFerla FM (2010) Synergistic interactions between Abeta, 
tau, and alpha-synuclein: Acceleration of neuropathology and cognitive decline. J Neurosci, 30, 7281-7289.

[16] Sabbagh MN, Adler CH, Lahti TJ, Connor DJ, Vedders L, Peterson LK, Caviness JN, Shill HA, Sue LI, Ziabreva I, Perry E, Ballard CG, Aarsland D, Walker DG, Beach TG (2009) Parkinson disease with dementia: Comparing patients with and without Alzheimer pathology. Alzheimer Dis Assoc Disord, 23, 295-297.

[17] Walhovd KB, Fjell AM, Amlien I, Grambaite R, Stenset V, Bjørnerud A, Reinvang I, Gjerstad L, Cappelen T, DueTønnessen P, Fladby T (2008) Multimodal imaging in mild cognitive impairment: Metabolism, morphometry and diffusion of the temporal-parietal memory network. Neuroimage, 45, 215-223.

[18] Whitwell JL, Shiung MM., Przybelski SA, Weigand SD, Knopman DS, Boeve BF, Jack CR (2008) MRI patterns of atrophy associated with progression to $\mathrm{AD}$ in amnestic mild cognitive impairment. Neurology, 70, 512-520.

[19] Jack CR, Knopman DS, Jagust WJ, Shaw LM, Aisen PS, Weiner MW, Petersen RC, Trojanowski JQ (2010) Hypothetical model of dynamic biomarkers of the Alzheimer's pathological cascade. Lancet Neurol, 9, 119-128.

[20] McKhann GM, Knopman DS, Chertkow H, Hyman BT, Jack CR Jr, Kawas CH, Klunk WE, Koroshetz WJ, Manly JJ, Mayeux R, Mohs RC, Morris JC, Rossor MN, Scheltens P, Carrillo MC, Thies B, Weintraub S, Phelps CH (2011) The diagnosis of dementia due to Alzheimer's disease: Recommendations from the National Institute on Aging-Alzheimer's Association workgroups on diagnostic guidelines for Alzheimer's disease. Alzheimers Dement, 7, 263-269.

[21] Eckerstrom C, Olsson E, Klasson N, Berge J, Nordlund A, Bjerke M, Wallin A (2015) Multimodal prediction of dementia with up to 10 years follow up: The Gothenburg MCI Study. J Alzheimers Dis, 44, 205-214.

[22] Murray ME, Lowe VJ, Graff-Radford NR, Liesinger AM, Cannon A, Przybelski SA, Rawal B, Parisi JE, Petersen RC, Kantarci K, Ross OA, Duara R, Knopman DR, Jack CR, Dickson DW (2015) Clinicopathologic and 11CPittsburgh compound B implications of Thal amyloid phase across the Alzheimer's disease spectrum. Brain, 138(Pt 5), 1370-1381.

[23] Parnetti L, Farotti L, Eusebi P, Chiasserini D, De Carlo C, Giannandrea D, Calabresi P, et al (2014) Differential role of CSF alpha-synuclein species, tau, and A $\beta 42$ in Parkinson's Disease. Front Aging Neurosci, 6, 53.

[24] Yarnall AJ, Breen DP, Duncan GW, Khoo TK, Coleman SY, Firbank MJ, Nombela C, Winder-Rhodes S, Evans JR, Rowe JB, Mollenhauer B, Kruse N, Hudson G, Chinnery PF, O'Brien JT, Robbins TW, Wesnes K, Brooks DJ, Barker RA, Burn DJ, ICICLE-PD Study Group (2014) Characterizing mild cognitive impairment in incident Parkinson disease: The ICICLE-PD Study. Neurology, 82, 308-316.

[25] Stav AL, Aarsland D, Johansen KK, Hessen E, Auning E, Fladby T (2015) Amyloid-beta and alpha-synuclein cerebrospinal fluid biomarkers and cognition in early Parkinson's disease. Parkinsonism Relat Disord, 21, 758-764.

[26] Parnetti L, Castrioto A, Chiasserini D, Persichetti E, Tambasco N, El-Agnaf O, Calabresi P (2013) Cerebrospinal fluid biomarkers in Parkinson disease. Nat Rev Neurol, 9 , 131-140.

[27] Guidi M, Paciaroni L, Paolini S, Scarpino O, Burn DJ (2015) Semantic profiles in mild cognitive impairment associated with Alzheimer's and Parkinson's diseases. Funct Neurol, 30, 113-118.
[28] Hildebrandt H, Fink F, Kastrup A, Haupts M, Eling P (2013) Cognitive profiles of patients with mild cognitive impairment or dementia in Alzheimer's or Parkinson's disease. Dement Geriatr Cogn Dis Extra, 3, 102-112.

[29] Rey A (1964) L'examen clinique en psychologie. Presses Univeritaires de France, Paris.

[30] Schmidt M (1996) Rey Auditory and Verbal Learning Test. A handbook. Western Psychological Services, Los Angeles.

[31] Meyers JE, Meyers KR (1995) Rey Complex Figure Test and Recognition Trial. Psychological Assessment Resources, Odessa, FL.

[32] Reitan RM, Wolfson D (1985) The Halstead-Reitan Neuropsychological Test Battery. Neuropsychology Press, Tucson.

[33] Benton AL, Hamsher K deS (1989) Multilingual Aphasia Examination. AJA Associates, Iowa City.

[34] Delis DC, Kaplan E, Kramer JH (2001) Delis and Kaplan Executive Functions System: Examiner's manual. The Psychological Corporation, San Antonio, TX.

[35] Fastenau PS, Denburg NL, Hufford BJ (1999) Adult norms for the Rey-Osterrieth complex figure test and for supplemental recognition and matching trials from the extended complex figure test. Clin Neuropsychol, 13, 30-47.

[36] Selnes P, Fjell AM, Gjerstad L, Bjørnerud A, Wallin A, Due-Tønnessen P, Grambaite R, Stenset V, Fladby T (2012) White matter imaging changes in subjective and mild cognitive impairment. Alzheimers Dement, 8, 112-121.

[37] Goetz CG, Tilley BC, Shaftman SR, Stebbins GT, Fahn S, Martinez-Martin P, Poewe W, Sampaio C, Stern MB, Dodel R, Dubois B, Holloway R, Jankovic J, Kulisevsky J, Lang AE, Lees A, Leurgans S, LeWitt PA, Nyenhuis D, Olanow CW, Rascol O, Schrag A, Teresi JA, van Hilten JJ, LaPelle N (2008) Movement Disorder Society-sponsored revision of the Unified Parkinson's Disease Rating Scale (MDSUPDRS): Scale presentation and clinimetric testing results. Mov Disord, 23, 2129-2170.

[38] Berardelli A, Wenning GK, Antonini A, Berg D, Bloem BR, Bonifati V, Brooks D, Burn DJ, Colosimo C, Fanciulli A, Ferreira J, Gasser T, Grandas F, Kanovsky P, Kostic V, Kulisevsky J, Oertel W, Poewe W, Reese JP, Relja M, Ruzicka E, Schrag A, Seppi K, Taba P, Vidailhet M (2013) EFNS/MDSES/ENS [corrected] recommendations for the diagnosis of Parkinson's disease. Eur J Neurol, 20, 16-34.

[39] Tomlinson CL, Stowe R, Patel S, Rick C, Gray R, Clarke CE (2010) Systematic review of levodopa dose equivalency reporting in Parkinson's disease. Mov Disord, 25, 26492653.

[40] Wallin A, Edman A, Blennow K, Gottfries CG, Karlsson I, Regland B, Sjogren M (1996) Stepwise comparative status analysis (STEP): A tool for identification of regional brain syndromes in dementia. J Geriatr Psychiatry Neurol, 9, 185199.

[41] Edman A, Mahnfeldt M, Wallin A (2001) Inter-rater reliability of the STEP protocol. J Geriatr Psychiatry Neurol, 14, 140-144.

[42] Royall DR, Mahurin RK, Gray KF (1992) Bedside assessment of executive cognitive impairment: The executive interview. J Am Geriatr Soc, 40, 1221-1226.

[43] Kiernan RJ, Mueller J, Langston JW, Van Dyke C (1987) The Neurobehavioral Cognitive Status Examination: A brief but quantitative approach to cognitive assessment. Ann Intern Med, 107, 481-485.

[44] Folstein MF, Folstein SE, McHugh PR (1975) "Mini-mental state". A practical method for grading the cognitive state of patients for the clinician. J Psychiatr Res, 12, 189-198. 
[45] Reisberg B, Gauthier S (2008) Current evidence for subjective cognitive impairment (SCI) as the premild cognitive impairment (MCI) stage of subsequently manifest Alzheimer's disease. Int Psychogeriatr, 20, $1-16$.

[46] Sjogren M, Vanderstichele H, Agren H, Zachrisson O, Edsbagge M, Wikkelso C, Skoog I, Wallin A, Wahlund LO, Marcusson J, Nägga K (2001) Tau and Abeta42 in cerebrospinal fluid from healthy adults 21-93 years of age: Establishment of reference values. Clin Chem, 47, 17761781.

[47] Hessen E, Reinvang I, Eliassen CF, Nordlund A, Gjerstad L, Fladby T, \& Wallin A (2014) The combination of dysexecutive and amnestic deficits strongly predicts conversion to dementia in young mild cognitive impairment patients: A report from the Gothenburg-Oslo MCI Study. Dement Geriatr Cogn Disord Extra, 4, 76-85.

[48] Litvan I, Goldman JG, Tröster AI, Schmand BA, Weintraub D, Petersen RC, Mollenhauer B, Adler CH, Marder K, Williams-Gray CH, Aarsland D, Kulisevsky J, RodriguezOroz MC, Burn DJ, Barker RA, Emre M (2012) Diagnostic criteria for mild cognitive impairment in Parkinson's disease: Movement Disorder Society Task Force Guidelines. Mov Disord, 27, 349-356.
[49] Morris JC, Heyman A, Mohs RC, Hughes JP, van Belle G, Fillenbaum G, Mellits ED, Clark C (1989) The Consortium to Establish a Registry for Alzheimer's Disease (CERAD). Part I. Clinical and neuropsychological assessment of Alzheimer's disease. Neurology, 39, 1159-1165.

[50] Oswald WD, Fleischmann UM (1997) Das Nürnberger Altersinventar (NAI). Hogrefe, Göttingen.

[51] Wechsler D (1987) Wechsler Memory Scale—Revised manual. Psychological Corporation, San Antonio, TX.

[52] Lezak MD, Howieson DB, Bigler ED, Tranel D (2012) Neuropsychological Assessment. Fifth Edition. Oxford University Press.

[53] Schear JM, Sato SD (1989) Effects of visual acuity and visual motor speed and dexterity on cognitive test performance. Arch Clin Neuropsychol, 4, 25-32.

[54] Auning E, Kjærvik VK, Selnes P, Aarsland D, Haram A, Bjørnerud A, Hessen E, Esnaashari A, Fladby T (2014) White matter integrity and cognition in Parkinson's disease: A cross-sectional study. BMJ Open, 4, e003976.

[55] Stav AL, Kunszt-Johansen K, Auning E, Kalheim LF, Selnes P, Bjørnerud A, Hessen E, Aarsland D, Fladby T (2015) Hippocampal subfield atrophy in relation to cerebrospinal fluid biomarkers and cognition in early Parkinson's disease: A cross-sectional study. NPJ Parkinsons Dis, 2, 15030. 